Medeiros, C. L. - Charakteristik

\title{
Caracterização: a obra de arte crítico-literária
}

\author{
[Charakteristik: the masterpiece of literary criticism] \\ http://dx.doi.org/10.1590/1982-883737565
}

\author{
Constantino Luz de Medeiros ${ }^{1}$
}

\begin{abstract}
Karl Wilhelm Friedrich Schlegel (1772-1829) regarded the Charakteristik as a masterpiece of literary criticism in which both the extrinsic and intrinsic aspects of the literary work should be taken into consideration and understood as an unity. According to this theory, the task of literary criticism was to reveal the tendency and the ideal of the work of literature through the observation and understanding of several aspects which belonged either to the letter or to the spirit of the work, or that might even transit between these two realms. The main purpose of this paper is to introduce and to discuss some aspects of Schlegels Philosophy of Characterization, as it is exposed in his Fragmente zur Poesie und Literatur, the Literary Notebooks, (1793-1803), and to demonstrate how the German critic concretized his theory in his Meister-Aufsatz, the Characterization of Wilhelm Meister's Apprenticeship, from 1798.
\end{abstract}

Key-words: Friedrich Schlegel; Charakteristik; literary criticism; philosophy of the history; Meister-Aufsatz

Resumo: Karl Wilhelm Friedrich Schlegel (1772-1829) compreendia a Charakteristik como uma obra de arte da crítica literária, na qual tanto os aspectos extrínsecos quanto os intrínsecos deveriam ser levados em consideração e compreendidos como uma unidade. De acordo com essa teoria, a tarefa do crítico de literatura era revelar a tendência e o ideal da obra literária através da observação e compreensão de certos aspectos que pertenceriam tanto à letra quanto ao espírito da obra, ou que poderiam transitar entre esses dois âmbitos. O intuito principal desse artigo é introduzir e discutir alguns aspectos da Filosofia da caracterização de Schlegel, exposta em seus Fragmente zur Poesie und Literatur, os Fragmentos sobre poesia e literatura (1793-1803), e demonstrar como o crítico alemão concretizou sua teoria no Meister-Aufsatz, o Ensaio sobre os anos de aprendizado de Wilhelm Meister, de Johann Wolfgang Goethe, de 1798.

Palavras-chave: Friedrich Schlegel; Caracterização; Crítica literária; filosofia da história; Meister-Aufsatz

\footnotetext{
${ }^{1}$ Universidade de São Paulo, Faculdade de Filosofia, Letras e Ciências Humanas, Departamento de Teoria Literária e Literatura Comparada, Av. Prof. Luciano Gualberto, 403, 05508-910, São Paulo, SP, Brasil.Email: constantinoluz@usp.br

Pandaemonium, São Paulo, v. 18, n. 25, Jun. /2015, p. 37-56.
} 


\section{Introdução}

Através da caracterização crítico-literária, a denominada Charakteristik, Friedrich SCHLEGEL busca concretizar a máxima de que um texto crítico-literário deve ser ele mesmo uma obra de arte, isto é, um complemento da criação artística, tornando a poesia mais poética e a crítica ainda mais crítica. Instrumento de reflexão sobre a literatura, a caracterização deve favorecer uma visão do todo da obra, de modo a estabelecer se ela alcançara seu ideal. Para tal fim, o crítico observa diversos aspectos: o contexto histórico da obra, a tradição literária; os elementos estéticos, estilísticos, linguísticos, filológicos, biográficos; a relação entre as partes e o todo da obra, e o lugar do escrito entre as outras criações do autor. Aliada aos aspectos formais, estruturais, e a matéria tratada, a caracterização leva igualmente em consideração algo que transita entre a letra e o espírito da obra. Entre as principais caracterizações de Schlegel encontram-se: a resenha sobre Os anos de aprendizado de Wilhelm Meister, romance de Johann Wolfgang Goethe, também conhecida como Über Meister, ou Meister-Aufsatz; a caracterização sobre as obras de Giovanni Boccaccio: Nachricht von den poetischen Werken des Johannes Boccaccio [Relato sobre as obras poéticas de Giovanni Boccaccio]; a caracterização sobre Forster: Georg Forster, fragment einer Charakteristik der deutschen Klassiker [Georg Forster, fragmento de uma caracterização do clássico alemão]; e, finalmente, a caracterização sobre Gotthold Ephraim Lessing: Über Lessing [Sobre Lessing] ${ }^{2}$.

Segundo KLUGE (2002: 167), o termo Charakter advém do francês caractère, que, por sua vez, tem origem no grego charaktér, uma variação de charássein, que significa cunhar, marcar, designar. Ainda de acordo com o autor, a palavra já possuía em grego um sentido literal e outro abstrato, isto é, ao mesmo tempo em que tinha o significado de marcar algo, também denotava algo como a marca moral, ou seja, uma qualidade principal de um homem. Em outros dicionários da época de Schlegel, como o AdELUng (1811: 1321) ou ainda o ThIBAULt (1804: 89), o termo Charakteristik tem igualmente a acepção de "sinal diferenciador", Unterscheidendes Merkmal, o que indica que Schlegel utilizou um termo da tradição histórica ou literária, inserindo-o no

\footnotetext{
${ }^{2}$ As caracterizações de Friedrich Schlegel foram publicadas nos anos de 1796 [Caracterização sobre o Woldemar, de Jacobi]; 1797 [Caracterização sobre Georg Forster]; 1797 [Caracterização de Lessing]; 1798 [Caracterização do Wilhelm Meister, de Goethe]; 1801[Caracterização sobre as obras poéticas de Giovanni Boccaccio]. (cf. SCHLEGEL 1967).
}

Pandaemonium, São Paulo, v. 18, n. 25, Jun. /2015, p. 37-56. 


\section{Medeiros, C. L. - Charakteristik}

contexto de sua teorização crítico-literária. MESSLIN (2011: 364) defende a tese de que a caracterização de Schlegel remonta à busca grega pela determinação do ethos na obra de arte, concretizando a filosofia moral do autor de Lucinde nas caracterizações. Assim, em sintonia com a acepção original do termo "caráter", a caracterização schlegeliana tem uma íntima relação com a determinação da singularidade da obra literária. Por outro lado, o nome pode ter sido uma influência advinda do âmbito das artes plásticas, onde a palavra Charakter se aproxima de arte do retrato, Porträtkunst, ou seja, a arte de delinear ou retratar as singularidades de alguém. Todavia, a mais provável razão para a escolha da palavra caracterização por Schlegel advém da tradição filosófica e literária encontrada pelo crítico nas obras de Teofrasto, Casaubon, La Bruyère, Joseph Hall e Shaftesbury, entre outros. BRUYÈRE (1995: 15) retoma em Les Caractères, obra de 1670, a antiga tradição de criar retratos sociais ou de costumes que surgira ainda na Antiguidade com o filósofo grego Teofrasto (c. 370 - 288 a. C.), cujo nome verdadeiro era Tírtamo de Ereso. A caracterização de perfis sociais inaugurada por Teofrasto é retomada pelo humanista Isaac Casaubon (1559-1614), o qual, ainda no ano de 1592, publica Prolégomènes à l'édition des Caractéres de Théophraste, cuja influência sobre Joseph Hall (1574-1656), e sua obra Characters of Vertues and Vices (1608) espalha o gênero da caracterização por toda a literatura europeia. É nessa tradição que se insere igualmente outra obra que provavelmente serviu de inspiração a Schlegel, o escrito de Antony Ashley Cooper, terceiro Conde de Shaftesbury (1671-1713), intitulado Characteristicks of men, manners, opinions and times, obra que teve treze edições até o ano de 1790. Após as diversas edições da obra de Shaftesbury o termo foi incorporado ao léxico crítico-literário, de modo que, na época de Schlegel, ele já possuía o significado de descrição de um quadro, situação, assim como a exposição e delineação das qualidades de uma pessoa ou obra.

A análise das caracterizações de Schlegel demonstra que esse tipo de exegese crítico-literária não se atém a um objeto único, podendo abarcar uma obra (Wilhelm Meister, Woldemar); um conjunto de obras (Relato sobre as obras poéticas de Giovanni Boccaccio); a produção crítica (ou política) de um autor (Georg Forster, Lessing); e até mesmo um panorama da poesia (A poesia antiga e a poesia moderna). O caráter inédito da caracterização reside principalmente na busca por algo além do que está dado no texto literário, ou seja, sua tendência, seu ideal. É com esse sentido que se deve entender a afirmação de Schlegel de que "a crítica se funda numa Ideia, antecipação divinatória

Pandaemonium, São Paulo, v. 18, n. 25, Jun. /2015, p. 37-56. 
Medeiros, C. L. - Charakteristik

de um todo orgânico ainda não realizado, mas por realizar num progresso infinito" (SUZUKI: 1998, 185). Ao estabelecer o ideal imanente à própria obra, o crítico tem como uma de suas prerrogativas fundamentais o reestabelecimento de um texto que, em seu devir, na realização desse ideal, representa uma tarefa infinita.

\section{A filosofia da caracterização}

Toda obra de arte romântica é poesia da poesia e poesia crítica, aproximando-se da caracterização.

(SCHLEGEL 1981: 134)

De modo semelhante a outros aspectos de sua teorização crítico-literária, a caracterização revela o esforço de Schlegel por estabelecer uma crítica universalmente válida. Nesse sentido, em alguns de seus Fragmentos sobre poesia e literatura, o crítico alemão busca sistematizar o gênero através de um esquema que denomina "dedução das categorias críticas, ou, filosofia da caracterização" (SCHLEGEL 1981: 132, fragmento 567). Nessa espécie de concepção arquitetônica da crítica literária, o autor de Lucinde divide a Charakteristik em tópicos. O esquema tem o intuito de classificar as categorias que devem ser consideradas na análise de uma obra de arte literária. Assim o fundamento da caracterização schlegeliana é o estabelecimento do caráter, ou da essência da obra:

Das Wesen, der substantielle Theil (das Herz seines Lebens) eines Kunstwerkes ist das, worauf alles andre hindeutet, woraus es entspringt, weshalb es da ist, der letzte Zweck und der erste Grund des Ganzen. Die Karakteristik erfordert gleichsam eine Geographie ein leichtes und korrektes Skelett; eine geistige und aesthetische Architektonik des Werkes, seines Wesens, seines Tons; und endlich: eine psychologische Genesis, die Entstehung aus seiner Veranlaßung, durch Gesetze und Bedingungen der menschlichen Natur. ${ }^{3}$

A análise crítica, filológica, filosófica, histórica, estilística - pois a caracterização observa igualmente os detalhes linguísticos e estilísticos de um autor, como é o caso da

\footnotetext{
${ }^{3} \mathrm{O}$ essencial, a parte substancial de uma obra de arte (o núcleo de sua existência) é o elemento para onde tudo aponta. É de lá que surge a obra, a razão de seu existir, bem como o fim último e a primeira razão do todo. A caracterização necessita de algo como uma geografia, um esqueleto da obra; precisa de uma arquitetura estética da obra, sua essência, seu tom, e, finalmente, uma gênese psicológica, a razão de seu surgimento pelas leis e condições da natureza humana (SCHLEGEL 1981: 132; fragmento 567). Todas as traduções de fragmentos ou textos de Friedrich Schlegel são de nossa autoria, com exceção daquelas nas quais está identificado o tradutor.
}

Pandaemonium, São Paulo, v. 18, n. 25, Jun. /2015, p. 37-56. 


\section{Medeiros, C. L. - Charakteristik}

caracterização das obras poéticas de Giovanni Boccaccio - deve se constituir em uma criação em segunda potência, sendo, ao mesmo tempo, crítica e crítica da crítica. Esses aspectos demonstram a singularidade do sistema crítico-literário de Schlegel, principalmente se forem levadas em consideração as poéticas normativas que vigoraram até pouco tempo antes de suas caracterizações. Ocupando a posição central nesse sistema encontra-se a essência da obra analisada, que para o crítico deve ser a primeira coisa a ser encontrada pelo crítico e caracterizador. Partindo dessa posição central ocupada pela essência [Wesen] ou caráter [Charakter] da obra, o crítico deve então analisar os aspectos intrínsecos e extrínsecos, ou seja, os elementos inerentes à obra, e sua inserção no contexto histórico e social em que foi produzida. Subordinados à essência ou caráter central da obra, o espírito e a letra são níveis hierárquicos com os quais outros elementos estão relacionados. Essa divisão entre a letra e o espírito da obra surge nos "Fragmentos sobre poesia e literatura", Fragmente zur Poesie und Literatur (SCHLEGEL 1981: 132), exposta através de um quadro, o qual reproduzimos abaixo:

[Figura 1; SCHLEGEL 1981: 132, fragmento 567).

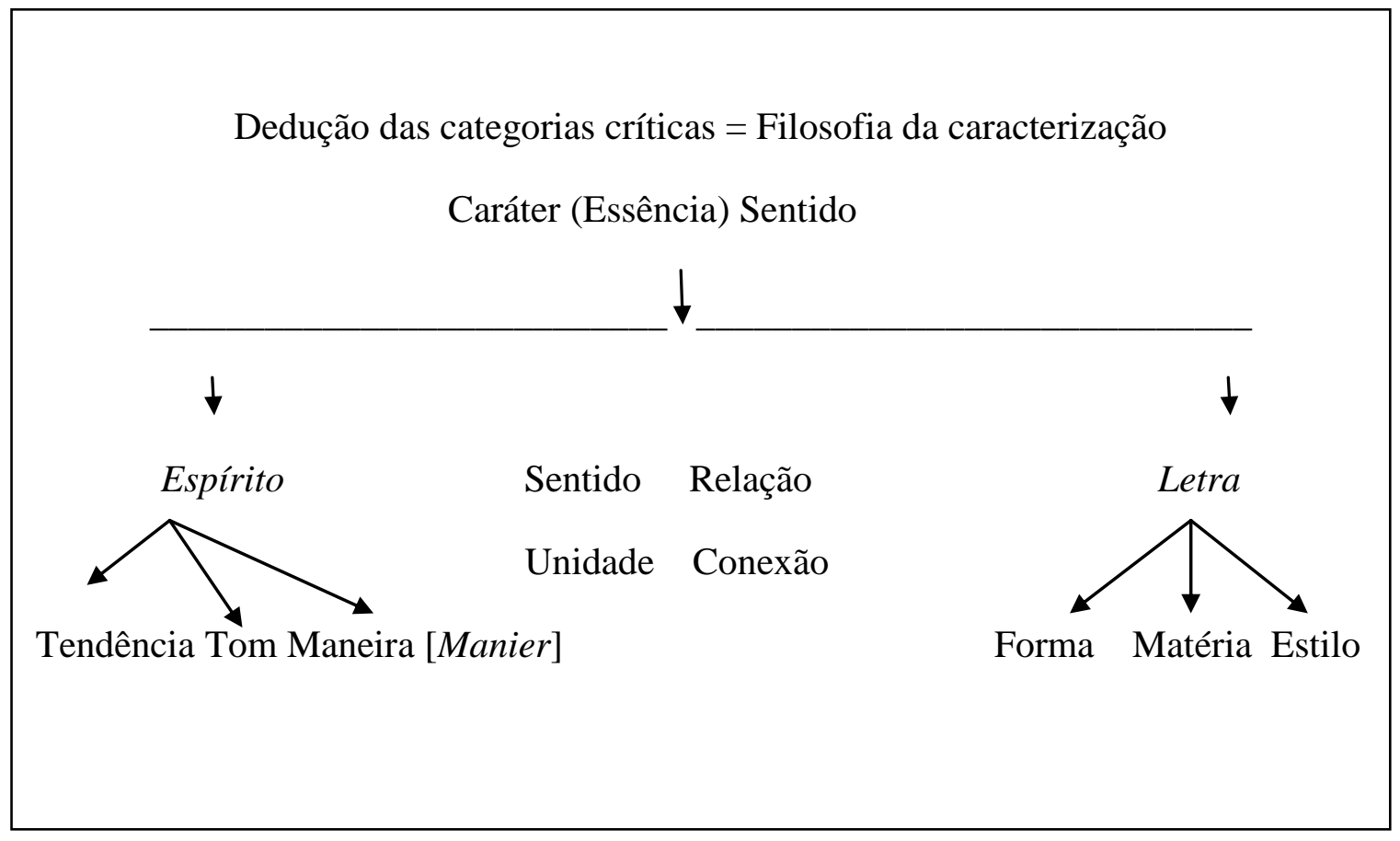




\section{Medeiros, C. L. - Charakteristik}

De acordo com o quadro acima, a tendência da obra, o tom e a maneira estão subordinados ao espírito, enquanto a forma, a matéria e o estilo se subsumem à letra do fenômeno literário. Em outro fragmento da mesma época, SCHLEGEL (1981: 122, fragmento 443) também afirma que o espírito de uma obra é sempre algo indeterminado, e, assim, incondicionado. Entre a letra e o espírito da obra caracterizada, o crítico ainda insere o sentido, a unidade, a relação e a conexão. Apesar da estrutura formal desse organograma, o qual divide a caracterização entre espírito e letra, Schlegel assevera em diversos trechos de sua obra que a caracterização de uma obra necessita de uma crítica divinatória, que possa levar em consideração algo que se move entre esses dois âmbitos. Assim, elementos como a tendência e o ideal não podem ser derivados apenas de um dos lados da obra, isto é, somente de sua letra ou de seu espírito, mas de uma aproximação recíproca entre os dois âmbitos. Outro aspecto interessante da filosofia da caracterização schlegeliana é o fato de que essa forma de crítica contempla um ponto de vista comum e outro transcendental. Em analogia ao bufão comum e o transcendental, os quais atuam através da atitude irônica, o crítico e caracterizador deve problematizar a obra de arte literária e, ao mesmo tempo, refletir de um modo autocrítico sobre sua própria atividade. A caracterização também se diferencia de outros gêneros crítico-literários como a resenha por seu caráter divinatório, pois, segundo o estudioso, a resenha se ocupa com obras de seu tempo, enquanto a caracterização também deve buscar o estabelecimento de algo que ainda inexiste, ou que se encontra ainda em tendência:

Eine Charakteristik ist ein Kunstwerk der Kritik, ein visum repertum der chemischen Philosophie. Eine Rezension ist eine angewandte und anwendende Charakteristik, mit Rücksicht auf den gegenwärtigen Zustand der Literatur und das Publikums. Übersichten, literarische Annalen sind Summen oder Reihen von Charakteristiken. Paralelen sind kritische Gruppen. Aus der Verknüpfung beider entspringt die Auswahl der Klassiker, das kritische Weltsystem für eine gegebne Sphäre der Philosophie oder der Poesie. ${ }^{4}$.

A tentativa de definir a individualidade da obra literária transforma a caracterização em uma extensão, um complemento da literatura. Esse fato pode ser observado na afirmação de que apenas indivíduos podem e devem ser caracterizados, pois, "tudo o

\footnotetext{
${ }^{4}$ Uma caracterização é uma obra de arte da crítica, um visum repertum da filosofia química. Uma resenha é uma caracterização aplicada ou que se aplica em vista do estado atual da literatura e do público. Panoramas, anais literários, são somas ou séries de caracterizações. Paralelos são grupos críticos. Da junção de ambos nasce a seleção de clássicos, o sistema cósmico crítico para uma dada esfera da filosofia ou poesia. (SCHLEGEL 1997: 140, fragmento 439, tradução de Márcio Suzuki).
} 
que deve ser criticado tem de ser um indivíduo, mas a individualidade não deve ser exposta na caracterização de modo histórico, mas de modo mímico" (SCHLEGEL 1981: 138, fragmento 634). Nesse sentido, o crítico se questiona sobre a possibilidade de se caracterizar outra coisa que não indivíduos. Na terminologia de Schlegel, a concepção de indivíduo pode significar um ser humano, uma obra, ou mesmo um conjunto de obras. Mas, de acordo com o crítico, apenas indivíduos clássicos, fossem eles obras ou homens, deveriam ser o assunto da caracterização (SCHLEGEL 1981: 142, fragmento 677). O mesmo ideal de indivíduo clássico se aplica ao ideal de crítico para Schlegel. Esse novo estudioso de literatura sabe da necessidade de ser "ele mesmo e, ao mesmo tempo, outra pessoa, para conseguir caracterizar uma obra individual." (SCHLEGEL 1981: 140, fragmento 654).

Assim, o crítico caracterizador deve igualmente ser capaz de compreender todo o desenvolvimento de uma obra, descrevendo cada passo de sua formação, pois caracterizar significa compreender profundamente um assunto, uma obra, entendendo seu espírito:

Der gute Kritiker und Charakteristiker muß treu, gewissenhaft vielseitig beobachten wie der Physiker, scharf messen wir der Mathematiker, sorgfältig rubriciren wie der Botaniker, zergliedern wie der Anatom, scheiden wie der Chemiker, empfinden wie der Musiker, nachahmen wie ein Schauspieler, praktisch umfassen wie ein Liebender, überschauen wie ein Philosoph, cyclisch studiren wie ein Bildner, streng wie ein Richter, religiös wie ein Antiquar, den Moment verstehn wie ein Politiker ${ }^{5}$.

No que concerne a estrutura, as caracterizações de Schlegel obedecem à sequência descrita em sua filosofia da caracterização, isto é, a busca pela singularidade da obra, de seu caráter central, ou, como no caso de indivíduos, a procura por traços significativos que diferenciam esse indivíduo de outros. Nessa primeira etapa da caracterização, um termo utilizado frequentemente é Grundzüge, que pode ser traduzido como "traço característico". Essa palavra é empregada pelo crítico para definir o que considera característico na obra, ou seja, o que a diferencia de outros escritos. Na caracterização de Georg Forster, um dos traços característicos é "a liberdade do espírito desse homem universal"; na caracterização sobre o Woldemar de Jacobi, "a reflexão filosófica"; nas

\footnotetext{
${ }^{5} \mathrm{O}$ bom crítico e caracterizador [Charakteristiker] deve observar de forma versátil, fiel e conscienciosa como o físico, medir e calcular milimetricamente como o matemático, classificar e rubricar atenciosamente como o botânico, dissecar como o anatomista, distinguir como o químico, sentir como o músico, imitar como o ator, compreender de forma prática como um amante, ter a visão do todo como um filósofo, estudar circularmente como um artista, ser severo como um juiz, religioso como um antiquário e entender o momento como um político. (SCHLEGEL 1981: 138, fragmento 635).
} 


\section{Medeiros, C. L. - Charakteristik}

Obras poéticas de Giovanni Boccaccio, "a representação objetiva através da forma breve"; na caracterização de Lessing, o argumento de que "Lessing foi um espírito revolucionário que provocou imensas erupções onde quer que tenha atuado" (SCHLEGEL 1967: 101). Do mesmo modo, na caracterização do Wilhelm Meister, Schlegel afirma que o caracterizador deve buscar o espírito, ou seja, "a individualidade absoluta" que paira sobre o escrito (SCHLEGEL 1967: 126). Após a delimitação do traço característico, o exegeta deve prosseguir em sua análise, buscando refletir sobre a forma e a matéria, indicar os acertos e erros, e verificar se o artista foi capaz de alcançar o objetivo proposto. Todos esses aspectos auxiliam a definir a essência da obra, a partir da qual é possível observar outros elementos estruturais. Além disso, o conhecimento histórico é imprescindível, pois, "para poder caracterizar um autor é necessário conhecer seu mundo, caso contrário não será possível conhecer a tendência, isto é, o interior da obra, o que ela deseja e o âmbito ao qual pertence" (SCHLEGEL 1963: 98, fragmento 840). Essa mesma preocupação com o contexto histórico é demonstrada na Charakteristik sobre Giovanni Boccaccio:

Mann kann den Charakter eines Dichters im ganzen nie mit einiger Richtigkeit treffen, bevor man nicht den Kreis der Kunstgeschichte gefunden hat, zu dem er gehört, das größere Ganze, von dem er selbst nur ein Glied ist. Man muß es mit solchen Konstruktionen, welche die einzige Grundlage jeder reellen Kunstgeschichte sind, eben so lange versuchen, bis man das Recht endlich gefunden zu haben sich durch mancherlei Bestätigungen versichern kann. Hat man nur den Geist der Kunst überhaupt, von der eine Geschichte gesucht wird, und fehlt es dabei nur nicht an Ernst und unermüdlichem Studium, so wird man sich über schlechten Erfolg in dem Versuch, die Entstehung des wirklich Gebildeten und die innere Organization dieser Entstehung und Bildung zu begreifen, nicht beklagen dürfen. ${ }^{6}$.

Desse modo, as caracterizações seguem uma série de ações: a definição da obra e do objetivo da caracterização; a busca por traços singulares; o estabelecimento da essência ou caráter da obra; a análise minuciosa dos escritos do autor; a discussão sobre os elementos relacionados ao contexto histórico; a procura pela tendência e a intenção da obra; os argumentos sobre a forma e a matéria tratadas na obra; a definição da

\footnotetext{
${ }^{6}$ Não se pode jamais acertar com precisão o caráter de um poeta em todos os seus aspectos antes que se tenha encontrado o círculo da história da arte ao qual ele pertence, o todo, do qual ele próprio é apenas um membro. Com tais construções, que são o único fundamento de toda história da arte real, deve-se experimentar até que se possa garantir, através de diversas confirmações, que se encontrou a coisa certa se apenas se possui o espírito da arte, do qual se procura uma história, e se também não falta um incansável estudo e seriedade, então não se deve queixar de um resultado medíocre na tentativa de compreender a origem, a organização interna e a constituição do que foi efetivamente formado. (SCHLEGEL 1967: 391).
} 


\section{Medeiros, C. L. - Charakteristik}

impressão absoluta que a obra pode deixar no leitor de qualquer época ou lugar, e, por fim, o estabelecimento do ideal individual. Mas, além dessa série de procedimentos formais, a caracterização pressupõe um crítico que tenha sentido para o todo, e que seja capaz de "entender um autor melhor do que ele próprio se entendeu" (SCHLEGEL 1967: 391).

\section{Tendência, impressão absoluta e ideal individual da obra}

Forma e estilo são intencionais, mas não o espírito, o tom, e a tendência. (SCHLEGEL 1967: 391).

Entre as inovações crítico-literárias postuladas por Schlegel em sua filosofia da caracterização encontram-se a tendência, a impressão e o ideal da obra literária. Esses aspectos da exegese crítico-literária surgem igualmente em outros textos do autor, mas, no contexto da teoria sobre a caracterização eles adquirem um significado especial. A palavra "tendência", por exemplo, foi utilizada pelo estudioso para definir não apenas fenômenos literários, mas também obras filosóficas e até mesmo adventos políticos de sua época. A palavra também se encontra inserida no centro da polêmica envolvendo o fragmento 216 da Athenäum, o qual afirmava que a "Revolução Francesa, o Meister, de Goethe, e a doutrina-da-ciência, de Fichte, eram as maiores tendências da época”. (SCHLEGEL 1997: 83, fragmento 216). Em seu escrito Da Ininteligibilidade [Über die Unverständlichkeit], o crítico afirma que toda a confusão relacionada ao fragmento se encontra na palavra "tendência" que, naquele contexto, tinha o significado de "algo que aponta em uma direção", "um ideal que ainda não se concretizara", e que seu tempo poderia também ser chamado de "época das tendências" (SCHLEGEL 1967: 367). O termo surge muitas vezes de um modo similar à "intenção do todo", indicando a essência daquilo que o autor se propôs a criar. É por essa razão que Schlegel também trata da tendência como "essência que advém da força interior":

Das innere Wesen und Streben eines Dinges heißt die Tendenz [...] Die Tendenz betrifft das innere Wesen des Gegenstandes. Das Wort Tendenz ist absichtlich gewählt 
worden, statt des Wortes Wesen, weil in dem Worte Tendenz zugleich enthalten ist der Begriff einer strebenden Kraft, als worin das innere Wesen besteht. ${ }^{7}$

Assim, o conceito de tendência está intimamente relacionado à intenção do conjunto da obra. Na conclusão de seu ensaio sobre Lessing, o estudioso indica igualmente que "há tendências secundárias e tendências principais, assim como existem intenções secundárias e principais, sendo que a junção de todos esses elementos compõe a intenção do todo" (SCHLEGEL 1967: 412). Para o autor de Lucinde, encontrar e delimitar a tendência de uma obra é uma das tarefas mais difíceis que se coloca ao caracterizador. Ao estabelecer a relação recíproca entre as partes, chegando a uma intuição do conjunto, o crítico deve definir o caráter da obra. É por essa razão que uma das palavras mais frequentes nas caracterizações é Eigentümlichkeit [singularidade, particularidade ou característica]. De acordo com essa visão, como todo indivíduo representa um microcosmo em relação ao todo, especificar a singularidade do indivíduo é caracterizar o universo (SCHLEGEL 1963: 292, fragmento 1157). O singular [Eigentümlich] - seja em uma obra de arte literária, um indivíduo, ou mesmo no conjunto de obras de um autor é um dos fundamentos do conceito de tendência. Um segundo aspecto a ser analisado pelo crítico de literatura na composição da caracterização é a impressão [Eindruck] da obra. Todavia, a impressão de que trata Schlegel não se assemelha à teoria do efeito da obra sobre o leitor, como era comum no século XVIII alemão. O estudioso almeja estabelecer a impressão absoluta que qualquer leitor, em qualquer época, pode apreender, e não a mera impressão momentânea e passageira. A falsa tendência que a primeira impressão de uma obra pode exercer sobre o leitor é teorizada por Schlegel em sua caracterização sobre Lessing:

Der erste Eindruck literarischer Erscheinungen aber ist nicht bloß unbestimmt: er ist auch selten reine Wirkung des Sache selbst, sondern gemeinschaftliches Resultat vieler mitwirkenden Einflüsse und zusammentreffenden Umstände. Dennoch pflegt man ihn ganz auf die Rechnung des Autors zu setzen, wodurch dieser nicht selten in ein durchaus falsches Licht gestellt wird. ${ }^{8}$.

\footnotetext{
${ }^{7}$ Denomina-se tendência ao que advém da força interior, da ânsia de uma coisa [...] A tendência compreende a essência interior do objeto caracterizado. A palavra foi escolhida intencionalmente, ao invés da palavra essência, porque na palavra tendência está contida ao mesmo tempo a concepção de uma força que aspira a algo [strebend Kraft], sendo aquilo mesmo que constitui a essência interior (SCHLEGEL 1964: 270).

${ }^{8}$ A primeira impressão dos fenômenos literários não é somente indefinida: ela também é raramente o efeito puro da própria da própria coisa, mas o resultado comum de diversas influências e condições reunidas e atuantes. Apesar disso, costuma-se atribuir essa impressão totalmente ao autor, o que tem por consequência o fato de, não raramente, esse autor ser compreendido sobre uma luz completamente falsa (SCHLEGEL 1967: 101).
} 


\section{Medeiros, C. L. - Charakteristik}

Ao afirmar que a crítica de uma obra deve ser capaz de expor ao leitor a impressão absoluta, o crítico chama a atenção para o caráter universal dessa impressão, já que não é qualquer impressão, mas apenas aquela que for necessária, evitando que a exegese literária se perca em juízos subjetivos. Segundo EICHNER (1970: 11), ao inserir a problematização sobre a impressão absoluta, isto é, um elemento universalmente válido em sua caracterização, e ao demonstrar que a exposição dessa impressão é a principal tarefa da exegese crítico-literária, Schlegel indica uma nova forma de se fazer crítica literária. René Wellek também aponta para a originalidade do conceito de impressão absoluta na caracterização:

Schlegel sugere principalmente sólidos e sóbrios princípios de interpretação [...] Em geral, define o objeto da crítica como sendo dar-nos um reflexo da obra, comunicar seu espírito peculiar, apresentar a impressão pura, de modo que, na sua apresentação, se verifique a cidadania artística do autor: não apenas um poema sobre um poema, a fim de deslumbrar por um momento; não meramente a impressão que uma obra produziu ontem ou produz hoje sobre esta ou aquela pessoa, mas a impressão que deverá sempre produzir sobre todas as pessoas cultas. Isto é reconhecer o apelo universal de todo julgamento crítico (WELLEK 1967: 6).

Ao tornar-se o instrumento de exposição da impressão necessária [Darstellung des notwendigen Eindrucks] a caracterização revela a singularidade da obra de arte literária. Assim, um de seus objetivos principais é transmitir ao leitor essa impressão absoluta da obra literária, cuja essência encontra-se entre o espírito e a letra. Para tal fím, o crítico precisa penetrar na obra de arte literária, de modo a estabelecer a essência, a tendência do escrito, e a impressão absoluta.

\section{A caracterização dos Anos de aprendizado de Wilhelm Meister, de Johann Wolfgang Goethe.}

A caracterização escrita por Schlegel sobre o Os anos de aprendizado de Wilhelm Meister, de Johann Wolfgang Goethe, é, de acordo com Mennemeier (1971: 221), “a expressão do entusiasmo de um crítico de literatura, o qual encontra in concreto algo que há muito tempo procurava”. De certo modo, essa afirmação corrobora o sentimento patente no ensaio de Schlegel sobre o romance de Goethe. Considerada pela crítica literária como uma obra prima dos estudos sobre literatura, a caracterização do Wilhelm 


\section{Medeiros, C. L. - Charakteristik}

Meister, também chamada de Meister-Aufsatz, representa um exemplo prático de "obra de arte crítico-literária" (como o crítico denominava esse tipo de ensaio crítico-literário) capaz de abordar os elementos intrínsecos e extrínsecos da obra, o contexto histórico, e oferecer uma compreensão panorâmica sobre as relações entre as partes e o todo. Para Wellek (1967: 29), o ensaio sobre Wilhelm Meister é justamente famoso porque consegue definir a atitude do autor, a impressão geral e o caráter particular de cada parte bem como os principais caracteres da ação.

Publicado no ano de 1798 na revista Athenäum, a caracterização parte da análise sobre o modo como as personagens são tratadas, o desenrolar de cada capítulo e os aspectos estruturais da narrativa. Através disso, Schlegel demonstra como esse tipo de escrito crítico-literário deve sondar não apenas os aspectos formais e estruturais, mas também "o espírito do conjunto da obra que se revela [também] através dos personagens" (SCHLEGEL 1967: 130). Para o autor de Lucinde, contrariando a regra clássica de representação de personagens das classes mais altas, a denominada Ständeklausel, a narrativa do romance goetheano principia com personagens comuns: "O que acontece e é discutido aqui não é extraordinário, e as primeiras figuras que surgem não são nem grandes e nem maravilhosas" (SCHLEGEL 1967: 130). O mesmo se dá com a narrativa, que para o crítico começa de um modo sutil e despretensioso:

Ohne Anmaßung und ohne Geräusch, wie die Bildung eines strebenden Geistes sich still entfaltet, und wie der werdende Welt aus seinem Innern Leise emporsteigt, beginnt die klare Geschichte. Was hier vorgeht und was hier gesprochen wird, ist nicht außerordentlich, und die Gestalten, welche zuerst hervortreten, sind weder groß noch wunderbar [...] Die Umrisse sind allgemein und leicht, aber sie sind genau, scharf und sicher. Der kleinste Zug ist bedeutsam, jeder Strich ist ein leiser und alles ist durch helle und lebhafte Gegensätze gehoben?.

De acordo com a leitura de Schlegel, ao expor personagens comuns em situações "nada excepcionais", o romance de Goethe busca arrebatar a simpatia do leitor. Essa aproximação pode ser sentida na afirmação do crítico de que "através da narrativa serena, o espírito se sente tocado de um modo suave, em toda parte, e mesmo sem conhecer as personagens ele as considera como conhecidas." (SCHLEGEL 1967: 126). O

\footnotetext{
${ }^{9}$ Sem presunção e sem barulho, assim como a formação de um espírito esforçado se desenvolve em silêncio, e como o mundo em devir surge a partir de seu interior, principia a clara história. O que ocorre e é dito aqui não é excepcional, e as figuras que primeiro aparecem não são nem grandiosas e nem maravilhosas [...] os traços são leves e simples, mas são exatos, nítidos e seguros. Mesmo o menor traço é significativo, cada linha é um leve aviso, e tudo é destacado por meio de contrastes claros e vivos (SCHLEGEL 1967: 126).
} 


\section{Medeiros, C. L. - Charakteristik}

sentimento de proximidade entre a matéria narrada e o leitor é descrito pelo autor da caracterização como o resultado feliz do modo de exposição [Die Art der Darstellung] que o narrador foi capaz de desenvolver, e que faz com que "qualquer pessoa formada tenha a impressão de se reencontrar na obra” (SCHLEGEL 1967: 127). A identificação do público leitor com a obra faz com que o acompanhamento das peripécias que acontecem no desenvolvimento do protagonista Wilhelm Meister, um típico filho da burguesia comerciante, ocorra de um modo despretensioso, "com um sorriso benevolente do leitor” (Schlegel 1967: 126). De acordo com Marcus Mazzari, ao revelar o desenvolvimento espiritual de um jovem burguês em busca de aventuras e de formação, o romance de Goethe também tem o mérito de levantar questões sobre a sociedade de seu tempo:

Com meios estéticos até então inéditos na literatura alemã, Goethe empreendeu a primeira grande tentativa de retratar e discutir a sociedade de seu tempo de maneira global, colocando no centro do romance a questão da formação do indivíduo, do desenvolvimento de suas potencialidades sob condições históricas concretas. Fez assim com que a obra paradigmática do Bildungsroman avultasse também como a primeira manifestação alemã realmente significativa do romance social burguês, na época já amplamente desenvolvido na Inglaterra e na França. (MAZZARI 2006: 9).

Nesse sentido, o fato de as personagens se parecerem homens de verdade e não "qualquer um" colabora para a identificação do leitor com o romance. Outro aspecto singular da caracterização é a questão da importância das personagens para o entendimento da obra. De acordo com Schlegel, as personagens interessam apenas enquanto instrumento para compreensão do conjunto da obra e não como mera especulação sobre os aspectos sociais que levaram Goethe a utilizar esse ou aquele procedimento. Desse modo, o crítico acredita que também não deve ter sido a intenção do autor/narrador apresentar as personagens em um grau mais intenso do que aquele necessário à verossimilhança e a representação do todo da obra:

Doch konnte es nicht seine Absicht sein, hier tiefer und voller darzustellen, als für den Zwecke des Ganzen nötig und gut wäre; und noch weniger konnte es seine Pflicht sein, einer bestimmten Wirklichkeit zu gleichen. Überhaupt gleichen die Charaktere in diesem Roman zwar durch die Art der Darstellung dem Porträt, ihrem Wesen nach aber sind sie ein unerschöpflicher Stoff und die vortrefflichste Beispielsammlung für sittliche und gesellschaftliche Untrersuchungen. ${ }^{10}$.

\footnotetext{
${ }^{10}$ Não pode ter sido essa a intenção dele [do autor/narrador], representar as personagens de um modo mais profundo e completo do que o necessário e útil; e menos ainda teria sido sua obrigação assemelhar a obra a uma determinada realidade de modo a cumprir o objetivo do todo. $\mathrm{Na}$ verdade, apesar de as personagens nesse romance se parecerem com retratos, em razão do modo de representação, ainda assim, segundo sua essência, elas são todas mais ou menos genéricas e alegóricas. Por isso mesmo, elas são
}

Pandaemonium, São Paulo, v. 18, n. 25, Jun. /2015, p. 37-56. 


\section{Medeiros, C. L. - Charakteristik}

Apesar de afirmar que a obra oferece matéria inesgotável, ou seja, a mais completa coleção de exemplos para investigações morais e sociais, Schlegel adverte para o perigo de investigações que buscassem reduzir seu escopo a esses elementos. Nesse sentido, o autor de Lucinde assevera que uma crítica que se concentrasse apenas em juízos morais sobre a particularidade das personagens "seria a mais infrutífera das tentativas" (SCHLEGEL 1967: 143). Assim como demonstrou em sua filosofia da caracterização, uma das tarefas do crítico é buscar a impressão absoluta que a obra de arte pode exercer sobre qualquer leitor em qualquer tempo. Após haver reconhecido e discutido diversos aspectos da estrutura do romance de Goethe, Schlegel aponta para o núcleo da narrativa, isto é, aquilo que organiza o conjunto da obra. Nesse caso, inserida no romance de Goethe se encontra a aproximação recíproca entre uma doutrina-da-arte e uma doutrinada-formação, as quais fundamentam os acontecimentos e a composição das personagens. De acordo com essa lógica, através do mundo do espetáculo em que o protagonista do romance se insere, o autor/narrador tem o mote para refletir sobre as artes, os gêneros poéticos e a formação do homem burguês. $O$ crítico acredita que a inserção do topos do teatro no romance de Goethe parece ter sido a maneira que o autor utilizou para aproximar os temas da arte e da formação, principalmente por sua semelhança com o universo das relações sociais.

Wenn wir auf die Lieblingsgegenstände aller Gespräche und aller gelegentlichen Entwicklungen, und auf die Lieblingsbeziehungen aller Begebenheiten, der Menschen und ihrer Umgebung sehen: so fällt in die Augen, daß sich alles um Schauspiel, Darstellung, Kunst und Poesie drehe. Es war so sehr die Absicht des Dichters, eine nicht unvollständige Kunstlehre aufzustellen, oder vielmehr in lebendigen Beispielen und Ansichten darzustellen [...] Bei dieser Absicht mußte die Schauspielerwelt die Umgebung und der Grund des Ganzen werden, weil eben diese Kunst nicht bloß die vielseitgste, sondern auch die geselligste aller Künste ist, und weil sich hier vorzüglich Poesie und Leben, Zeitalter und Welt berühren, während die einsame Werkstätte des bildenden Künstlers weniger Stoff darbietet, und die Dichter nur in ihrem Innern als Dichter leben, und keinen abgesonderten Künstlerstand mehr bilden. ${ }^{11}$.

matéria inesgotável e a mais perfeita coleção de exemplos para investigações morais e sociais (SCHLEGEL 1967: 143).

11 Se olharmos para os assuntos favoritos de todas as conversas, e de todos os desenvolvimentos ocasionais, e para as relações favoritas em todas as ocasiões, os homens e seu meio: salta aos olhos o fato de que tudo gira em torno do espetáculo, da encenação, da arte e da poesia. A verdadeira intenção do poeta foi estabelecer uma completa doutrina poética, ou melhor, expô-la através de exemplos e opiniões vivas [...] Com essa intenção, o mundo teatral tinha de tornar-se o meio e o fundamento do todo, não apenas porque essa arte é a mais variada, mas também a mais sociável de todas as artes, e porque nela se aproximam da melhor maneira poesia, vida, época e mundo, enquanto a oficina solitária do artista plástico oferece menos matéria, e os poetas vivem como poetas apenas interiormente, já não formando mais uma classe artística especial (SCHLEGEL 1967: 132).

Pandaemonium, São Paulo, v. 18, n. 25, Jun. /2015, p. 37-56. 
Ao comentar o desenvolvimento e a adequação e aprendizado do protagonista em sua procura pela compreensão da sociedade de seu tempo, Schlegel afirma que "cada traço singular [Charakter] de Wilhelm Meister é exposto através de outro lado notável, e em uma nova luz, pois, ele precisa aprender em toda parte" (SCHLEGEL 1967: 129). A experiência do protagonista é descrita com detalhes que indicam a importância desse tipo de formação para o homem burguês do final do século XVIII alemão. O duplo movimento realizado por Wilhelm Meister, ao sair de si e entrar no mundo, na sociedade, é descrito por Schlegel em termos de uma experiência "que mescla recordações alegres e dolorosas, pairando entre a plenitude dos desejos, a melancolia e a esperança" (SCHLEGEL 1967: 129). Assim, os anos de formação do protagonista também representam um conflito entre dois aspectos diametralmente opostos, ou seja, uma "incongruência entre a atividade burguesa que ele deve assumir, voltada para o acúmulo de dinheiro e propriedades, e o forte impulso de autoaprimoramento" (MAZZARI 2006: 12). Nesse sentido, a experiência representada pelo personagem principal da obra de Goethe em face do mundo burguês dos filisteus é, de certo modo, traumática. Ao abandonar a formação destinada pelos pais e buscar um mundo de aventuras, sobretudo, com um grupo teatral, Wilhelm Meister é signo de um grande paradoxo no universo dos jovens do final do século e começo do XIX. Nessa sociedade constituída por estratos sociais estanques, a tentativa de conseguir uma visão de mundo cosmopolita e universal era um privilégio apenas dos nobres. É possível observar essa característica da sociedade alemã no século XVIII através do diálogo entre o protagonista Wilhelm Meister e Serlo:

Wäre ich ein Edelmann, so wäre unser Streit bald abgetan; da ich aber nur ein Bürger bin, so muß ich einen eigenen Weg nehmen, und ich wünsche, daß Du mich verstehen mögest. Ich weiß nicht, wie es in fremden Ländern ist, aber in Deutschland ist nur dem Edelmann eine gewisse allgemeine, wenn ich sagen darf personelle Ausbildung möglich. Ein Bürger kann sich Verdienst erwerben und zur höchsten Not seinen Geist ausbilden; seine Persönlichleit geht aber verloren, er mag sich stellen wie er will ${ }^{12}$

O duplo movimento realizado por Wilhelm Meister, ao sair de si e entrar no mundo, na sociedade, é descrito por Schlegel em termos de uma experiência "que mescla

\footnotetext{
${ }^{12}$ Se eu fosse um nobre, nosso conflito logo se resolveria, porém, como sou apenas um burguês, devo então trilhar meu próprio caminho, e espero que você possa me compreender. Não sei como deve ser em países estrangeiros, mas, na Alemanha, apenas ao nobre é dada a possibilidade de conseguir uma formação universal e, se posso dizer, pessoal. Um burguês pode adquirir méritos e desenvolver seu espírito ao extremo, mas, sua personalidade estará perdida, apresente-se ele do modo que quiser. (GOETHE 2005: 260).
} 


\section{Medeiros, C. L. - Charakteristik}

recordações alegres e dolorosas, pairando entre a plenitude dos desejos, a melancolia e a esperança" (SCHLEGEL 1967: 129). A descrição do desenvolvimento espiritual de Wilhelm Meister segue a mesma lógica conflituosa que caracteriza a dualidade entre o interior do jovem sonhador e a dura realidade do mundo dos filisteus. Essa oposição já se encontra muito viva no final do primeiro capítulo do livro, onde, segundo Schlegel, "o entendimento maduro desse homem culto parece estar separado por um imenso abismo da imaginação florescente do jovem amante" (SCHLEGEL 1967: 128). Apesar disso, o intuito da formação da personagem é o aprendizado, mesmo sabendo de antemão que "não lhe faltarão tentações probatórias" (SCHLEGEL 1967: 129). O desacerto entre a formação destinada pelos pais de Wilhelm e a vontade do protagonista pode ser compreendido quando se leva em consideração a biografia da maioria dos jovens do primeiro romantismo alemão, inclusive a de Novalis e de Friedrich Schlegel. Além de ocupar com a descrição das principais características de cada personagem, o crítico aborda de um modo singular como os acontecimentos e as personagens se misturam no romance de um modo mágico e coeso, demonstrando como "o espírito dessa massa se revela" (SCHLEGEL 1967: 130).

Um aspecto formal analisado pelo crítico em seu ensaio sobre o Meister (que não havia surgido em sua filosofia da caracterização) é o conceito de "desenvolvimento secundário" [Nebenausbildung] da narrativa, o qual pode ser descrito como um movimento duplo do autor. Em um plano ocorre o desenvolvimento dos personagens e os acontecimentos, enquanto em um plano secundário são preparados eventos posteriores. Esse movimento acontece sem que um plano interfira no outro, "sem atrapalhar nem o mínimo deleite com o acontecimento presente" (SCHLEGEL 1967: 128). $\mathrm{O}$ autor de Lucinde verifica a presença do desenvolvimento secundário principalmente no encerramento do primeiro livro "cujo final se assemelha a uma música espiritual" (SCHLEGEL 1967: 128). De acordo com Schlegel, tão importante como compreender cada detalhe e se deixar levar pela imaginação poética do artista é não perder de vista o conjunto, o todo da obra. A referência à relação entre as partes e o todo na obra de arte literária é uma constante nas caracterizações:

Es ist schön und notwendig, sich dem Eindruck eines Gedichtes ganz hinzugeben, den Künstler mit uns machen zu lassen, was er will, und etwa nur im einzelnen das Gefühl durch Reflexion zu bestätigen und zum Gedanken zu erheben, und wo es noch zweifeln oder streiten dürfte, zu entscheiden und zu ergänzen. Dies ist das Erste und das Wesentlichste. Aber nicht minder notwendig ist es, von allem Einzelnen abstrahieren zu können, das Allgemeine schwebend zu fassen, eine Masse zu 
überschauen, und das Ganze festzuhalten, selbst dem Verborgensten nachzuforschen und das Entlegenste zu verbinden [...]. So mögen wir uns gern dem Zauber des Dichters entreißen, nachdem wir uns gutwillig haben von ihm fesseln lassen, mögen am liebsten dem nachspähn, was er unserm Blick entziehen oder doch nicht zuerst zeigen wollte, und was ihn doch am meisten zum Künstler macht: die geheimen Absichten, die er im stillen verfolgt, und deren wir beim Genius, dessen Instinkt zur Willkür geworden ist, nie zu viele voraussetzen können. Der angeborne Trieb des durchaus organisierten und organisierenden Werks, sich zu einem Ganzen zu bilden, äußert sich in den größeren wie in den kleineren Massen. Keine Pause ist zufällig und unbedeutend; und hier, wo alles zugleich Mittel und Zweck ist, wird es nicht unrichtig sein, den ersten Teil unbeschadet seiner Beziehung aufs Ganze als ein Werk für sich zu betrachten ${ }^{13}$.

Apesar de considerar que o romance conseguiu concretizar seu ideal individual de obra, tornando-se até mesmo o paradigma de um novo gênero, o reconhecimento positivo de Schlegel sobre o Wilhelm Meister encontra-se no fato de que a obra não buscava apenas teorizar sobre as artes, os gêneros poéticos, ou estabelecer novos padrões sociais. Além disso, o romance tinha a intenção de revelar “o grande espetáculo da própria humanidade e a arte de todas as artes, a arte de viver". (SCHLEGEL 1967: 143). O encontro propício entre a doutrina da arte e a doutrina da vida, entre a criação artística e a reflexão crítico-literária que se encontra inserido no Meister foi abordado por Schlegel também em um trecho denominado Versuch über den verschiedenen Styl in Goethes Früheren und späteren Werken [Ensaio sobre as diferenças de estilo nas obras juvenis e tardias de Goethe], da obra Conversa sobre a poesia. No escrito, o personagem de Marcus afirma que o romance foi inicialmente pensado apenas como um romance artístico, onde se representa uma doutrina da arte, mas, ainda de acordo com o personagem, "a própria obra teria sido surpreendida pela tendência de seu gênero, se transformando em algo muito maior do que sua primeira intenção, de modo que se junta

\footnotetext{
${ }^{13}$ É belo e necessário se entregar completamente à impressão de um poema, deixar o artista fazer conosco o que ele quiser, e, por meio da reflexão, apenas confirmar o sentimento em detalhes, elevando-o ao pensamento, de modo a poder decidir e complementar qualquer dúvida ou conflito remanescente. Esse é o primeiro e mais importante passo. Mas não é menos necessário poder abstrair de todo detalhe, compreender o que paira suspenso, passando os olhos pela parte, e apreendendo o todo, de modo a investigar até o mais recôndito e relacionar o mais remoto [...] Nós gostamos muito de nos libertar da magia do poeta, depois que nos deixamos de boa vontade cativar por ele, apreciamos, sobretudo, espiar o que ele quis afastar de nosso olhar, ou não quis logo nos mostrar, aquilo que posteriormente mais contribuiria para torná-lo um artista: os desígnios secretos que ele silenciosamente segue, e que nós, em se tratando do gênio, cujo instinto tornou-se arbítrio, jamais poderemos pressupor quantos são. $\mathrm{O}$ impulso nato da obra completamente organizada e organizadora, de modo a se transformar em um todo, exterioriza-se tanto nas partes maiores, quanto nas menores. Nenhuma pausa é ocasional e insignificante; e aqui, onde tudo é ao mesmo tempo meio e fim, não será incorreto considerar a primeira parte, sem prejuízo de sua relação com o todo, uma obra em si. (SCHLEGEL 1967: 131).
} 
a seu plano inicial uma doutrina da formação da arte da vida" (SCHLEGEL 1967: 346). Assim, ao ultrapassar as fronteiras de sua intenção original e fundamentar um novo gênero de romance, a obra representa os anos de aprendizado "onde nada será aprendido a não ser existir e viver de acordo com seus princípios singulares e sua natureza indômita" (SCHLEGEL 1967: 141). De certo modo, o romance de Goethe inaugura uma nova fase nos estudos literários, não apenas por ser a primeira manifestação do romance social burguês em língua alemã, introduzindo o conceito de romance de formação, mas, por contribuir de forma significativa para a alteração no modo com que se praticava a crítica literária de seu tempo:

Vielleicht soll man es also zugleich beurteilen und nicht beurteilen; welches keine leichte Aufgabe zu sein scheint. Glücklicherweise ist es eben eins von den Büchern, welche sich selbst beurteilen, und den Kunstrichter sonach aller Mühe überheben. Ja es beurteilt sich nicht nur selbst, es stellt sich auch selbst dar. Eine bloße Darstellung des Eindrucks würde daher, wenn sie auch keins der schlechtesten Gedichte von der beschreibenden Gattung sein sollte, außer dem, daß sie überflüssig sein würde, sehr den kürzern ziehen müssen; nicht bloß gegen den Dichter, sondern sogar gegen den Gedanken des Lesers, der Sinn für das Höchste hat, der anbeten kann, und ohne Kunst und Wissenschaft gleich weiß, was er anbeten soll, den das Rechte trifft wie ein Blitz $^{14}$.

Quando se leva em consideração a filosofia da caracterização é possível compreender a singularidade e a importância que o Wilhelm Meister adquire para Schlegel. Desse modo, Goethe é considerado como aquele que inaugura a terceira fase da poesia romântica, e seu romance indica o início de um caminho que levará a uma forma futura de exteriorização literária denominada poesia romântica, universal e progressiva. É também com vistas ao lugar histórico da obra que se compreende a afirmação de Schlegel de que "aquele que caracterizasse devidamente o Meister teria em verdade dito o que ocorre agora na poesia. E, no que concerne à crítica poética, não precisaria fazer mais nada" (SCHLEGEL 1967: 162, fragmento 120).

\footnotetext{
${ }^{14}$ Talvez seja necessário julgar e não julgar esse livro; o que não parece ser uma tarefa fácil. Por sorte, esse é exatamente um daqueles livros que julgam a si mesmos, poupando o crítico de qualquer esforço. $\mathrm{Na}$ verdade, ele não apenas se julga como também expõe a si mesmo. Uma mera exposição da impressão, mesmo se não fosse uma das piores obras do gênero descritivo, além de supérflua estaria em desvantagem não somente em relação ao poeta, mas até mesmo em face do pensamento do leitor que possuísse o sentido para o que é mais elevado, que tem a capacidade de adorar, e, mesmo sem arte ou ciência, sabe o que deve adorar, a quem a justiça atinge feito um raio. (SCHLEGEL 1967: 133).
} 


\section{Conclusão}

A Charakteristik, ou caracterização crítico-literária, pode ser considerada um dos primeiros exemplos de obra crítico-literária, no sentido moderno do termo. Buscando definir os aspectos intrínsecos e extrínsecos de uma obra de arte literária, bem como os elementos que transitam entre esses dois âmbitos, a caracterização difere de um ensaio e de uma resenha por considerar não apenas o que é dado na letra da obra, mas aquilo que se encontra em seu devir. Desse modo, Schlegel postula que apenas uma crítica divinatória e genial seria capaz de apreender toda a dimensão da obra, sua tendência e seu ideal. A caracterização realizada por Schlegel sobre o romance de Goethe Os anos de aprendizado de Wilhelm Meister é considerada pela crítica como um exemplo inovador de análise crítico literária para seu tempo. A partir de sua concepção de ironia romântica enquanto procedimento literário que instaura a reflexão crítico-literária na obra, Schlegel indica a necessidade do estabelecimento de um tipo de crítica de literatura que leve em consideração a existência de obras que "criticam e expõem a si mesmas" (Schlegel 1967: 133), como o romance de Goethe. Para o estudioso, o Wilhelm Meister inaugura uma nova era da literatura. Ao buscar a definição de elementos como a tendência, a impressão absoluta e o ideal individual da obra de arte literária, as caracterizações são exemplos do que o estudioso denominava de "crítica absoluta”, espécie de crítica literária que visa demonstrar aspectos para os quais a obra apenas aponta, que não podem ser facilmente reconhecidos em sua letra. Assim, a teoria crítico-literária de Schlegel indica que é necessário compreender algo que transita entre o espírito e a letra da obra, procurando distinguir se o seu ideal foi alcançado.

\section{Referências bibliográficas}

ADELUNG, Johann Christoph. Grammatisch-Kritischen Wörterbuch der Hochdeutschen Mundart. Wien: Bauer Verlag, 1811, p. 1321. THIBAUT, M. A. Wörterbuch der französichen und deutschen Sprache. Braunschweig: Georg Westermann, 1804, p. 89.

EICHNER, Hans. Friedrich Schlegels Theorie der Literaturkritik. In: VON WIESE, Benno; MOSER, Hugo. Deutsche Philologie. Berlin: Erich Schmidt Verlag, 1970, volume 88, p. 11.

GoETHE, Johann Wolfgang. Wilhelm Meister. Die Lehrjahre. Die Wanderjahre. Düsseldorf: Patmos Verlag, 2005.

Pandaemonium, São Paulo, v. 18, n. 25, Jun. /2015, p. 37-56. 


\section{Medeiros, C. L. - Charakteristik}

Os anos de aprendizado de Wilhelm Meister. São Paulo: Editora 34, 2006. Tradução de Nicolino Simone Neto.

KLUGE, Friedrich. Etymologisches Wörterbuch der deutschen Sprache. Berlin - New York: Walter de Gruyter, 2002.

LA BRUYERE, Jean de. Les Caractères ou les moeurs de ce siècle. Paris : Librairie Générale Française, 1995.

MAZZARI, Marcus Vinícius. Apresentação. In: GOETHE, Johann Wolfgang. Os anos de aprendizado de Wilhelm Meister. São Paulo: Editora 34, 2006. Tradução de Nicolino Simone Neto.

MENNEMEIER, Franz Norbert. Friedrich Schlegels Poesiebegriff dargestellt anhand der literaturkritischen Schriften. Die romantische Konzeption einer objektiven Poesie. München: Wilhelm Fink Verlag, 1971.

SCHLEGEL, Friedrich. Kritische Friedrich Schlegel Ausgabe. Paderborn: Ferdinand Schöningh, 1964. [Volume XIII]

. Kritische Friedrich Schlegel Ausgabe. Paderborn: Ferdinand Schöningh, 1967. [Volume II].

Kritische Friedrich Schlegel Ausgabe. Paderborn: Ferdinand Schöningh, 1981. [Volume XVI]. Suzuki.

O dialeto dos fragmentos. São Paulo: Iluminuras, 1997. Tradução de Márcio

SHAFTERSBURY, Anthony Ashley Cooper. Characteristicks of men, manners, opinions, times. Oxford: Clarendon Press, 1999.

SUZUKI, Márcio. O gênio romântico. Crítica e história da filosofia em Friedrich Schlegel. São Paulo: Iluminuras, 1998.

THIBAUT, M. A. Wörterbuch der französichen und deutschen Sprache. Braunschweig: Georg Westermann, 1804, p. 89.

WelleK, René. História da Crítica Literária. Friedrich Schlegel. São Paulo: Editora Herder, 1967, p. 6. Vol. III.

Recebido em 01/03/2015

Aceito em 05/05/2015

Pandaemonium, São Paulo, v. 18, n. 25, Jun. /2015, p. 37-56. 